\title{
Finite element analysis of composite concrete-timber beams
}

\section{Análise de vigas mistas de concreto e madeira pelo método dos elementos finitos}

N. C. S. FORTI nadia.cazarim@puc-campinas.edu.br

T. L. D. FORTI forti@simworx.com.br

A. E. P. G. A. JACINTHO a anajacintho@puc-campinas.edu.br

L. L. PIMENTEL a lialp@puc-campinas.edu.br

\begin{abstract}
In the search for sustainable construction, timber construction is gaining in popularity around the world. Sustainably harvested wood stores carbon dioxide, while reforestation absorbs yet more $\mathrm{CO} 2$. One technique involves the combination of a concrete slab and a timber beam, where the two materials are assembled by the use of flexible connectors. Composite structures provide reduced costs, environmental benefits, a better acoustic performance, when compared to timber structures, and maintain structural safety. Composite structures combine materials with different mechanical properties. Their mechanical performance depends on the efficiency of the connection, which is designed to transmit shear longitudinal forces between the two materials and to prevent vertical detachment. This study contributes with the implementation of a finite element formulation for stress and displacement determination of composite concrete-timber beams. The deduced stiffness matrix and load vector are presented along to numerical examples. Numerical examples are compared to the analytical equations available in Eurocode 5 and to experimental data found in the literature.
\end{abstract}

Keywords: composite structures, finite element method and sustainable structures.

\section{Resumo}

A madeira tem se destacado na produção de edificações sustentáveis, principalmente pela possibilidade de emprego de madeiras provenientes de florestas plantadas. A combinação de vigas de madeira com um tabuleiro de concreto armado ligados entre si por conexões flexíveis é uma alternativa que traz aumento de rigidez à estrutura, ameniza problemas de durabilidade, quando exposta às intempéries, e melhora seu desempenho acústico, se comparada à uma estrutura em madeira. As estruturas mistas são constituídas pela associação de materiais com diferentes propriedades mecânicas e seu desempenho mecânico depende da eficiência da ligação entre eles. Os conectores flexíveis são responsáveis pela transmissão de forças de cisalhamento entre os dois materiais e por evitar o desprendimento vertical. Esta pesquisa desenvolveu e implementou uma formulação de elementos finitos para cálculo dos esforços internos da estrutura mista de concreto e madeira. A matriz de rigidez e o vetor de carga deduzidos são apresentados juntamente com exemplos numéricos e seus resultados são comparados com as equações analíticas do Eurocode 5 e resultados experimentais da literatura.

Palavras-chave: estruturas mistas, elementos finitos e estruturas sustentáveis. 


\section{Introduction}

Composite structures combining materials with different mechanical properties offer an alternative to the civil construction industry. The technique provides reduced costs, environmental benefits and a better acoustic performance when compared to timber structures, while maintaining structural safety.

Concrete-timber composite systems may be applied to the construction of bridges, improving the bridge stiffness, resulting in smaller displacements and increasing natural frequencies of vibration.

The deck floor is composed of a concrete slab connected to timber beams aiming for the two materials to work together. The level of stress transfer between the concrete slab and the timber beam defines the mechanical behavior of the composite structure. It may be considered as a monolithic structure, when there is no slip in the region of contact, or it may behave as a non-monolithic structure when relative longitudinal displacement is observed.

The concrete slab protects the timber beams against direct weathering, surface abrasion and fire, improves the vibration performance and its maximum load when compared to timber bridges. The maximum load may increase by a factor of the order of two and the stiffness by three or four times according to CECCOTTI [1]. The relative lightness of composite materials and the possibility of using glued laminated timber (GLULAM) are factors that contribute to its prefabricated production.

\subsection{Connection systems for concrete-timber composite structures}

TARANTINO and DEZI [2] describes the necessity of studying the connection systems, which are responsible for transmitting the longitudinal shear forces in the interface of the two combined materials along the length of the beam.

Analyzing the connection of timber components, RACHER [3] highlights the major importance of the connection system, since its behavior directly affects the distribution of forces in the components and, as a consequence, in the structure deformations.

According to SORIANO [4] the connection system may be characterized as rigid or semi-rigid (flexible), Figure [1]. An example of rigid connection is the use of epoxy structural adhesive throughout the entire contact surface between the two materials, GIRHAMMAR and GOPU [5]. The rigid connection consists of the ful integration of the cross section and the structure behaves as a monolithic structure. Studies developed in Brazil, by directly gluing timber beams to structural elements of reinforced concrete, were presented by NICOLAS [6]. SORIANO [4] also tested T-shaped timber-concrete beams, where the timber web was glued to the concrete slab.

In the semi-rigid connection system, the attachment between the two materials may be done using steel pins, nails, screws, bolts or metal profiles. The semi-rigid connection performs a partial interaction of the cross section, with a relative displacement (slip) between the two materials.

\subsection{Models for the analysis of composite beams}

The main mathematical models for describing the mechanical behavior of composite structures proposed in the literature are based on the equilibrium equations and on energy principles. Unlike concrete-steel composite structures, there is insufficient standard specification for concrete-timber structures. For concretesteel structures, it can be cited the BS 5400 [7] or the Brazilian NBR8800/02 [8]. However, there is no Brazilian standard regarding the design of concrete-timber structures. An international standard that can be cited is the EUROCODE 5 [9].

\subsubsection{The EUROCODE 5 model for the analysis of composite beams}

Both the EUROCODE 5 [9] and the DIN 1052 [10] consider the flexibility of the connection system, and the relative displacement between the materials, by adopting an effective bending stiffness parameter $(E I)_{e f}$ which is calculated according to Equation [1]. Equation [1] is a function of the shape of the cross section, the Young's modulus of the materials, the spacing of connectors and its slip modulus.

$$
(E I)_{e f}=E_{c} I_{c}+y_{c} E_{c} A_{c} a_{c}^{2}+E_{w} I_{w}+y_{w} E_{w} A_{w} a_{w}^{2}
$$

In Equation [1] $E_{c}, E_{w}, I_{c}, I_{w}, A_{c}$ and $A_{w}$ are Young's modulus, the moment of inertia and the cross section areas of the concrete

Figure 1 - Vertical displacement of a composite beam

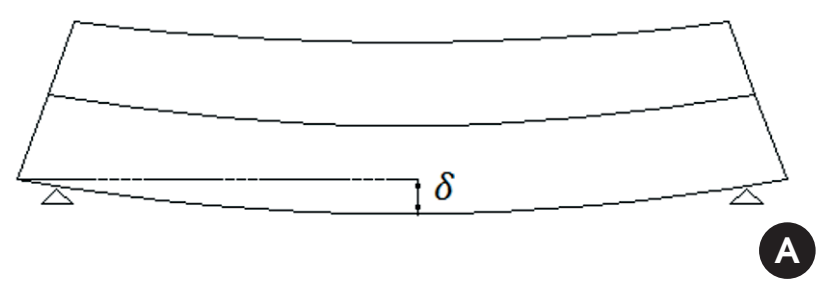

Rigid connection

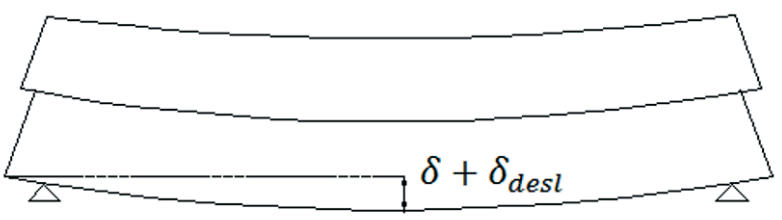

B 
Figure 2 - Cross section of a T-shaped composite beam and normal stresses on bending. Source: adapted from the EUROCODE 5 (9)

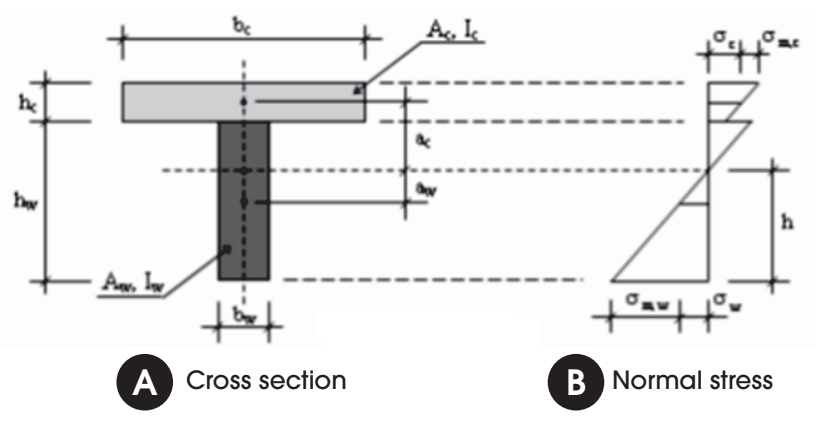

and timber elements respectively; $y_{c}$ is the partial factor of the slab, calculated according to Equation [2]; $y_{w}=1,0$ is the partial factor of the web; $a_{c}$ and $a_{w}$ are the distances indicated in Figure [2] calculated by Equations [3] and [4]; $l$ is the length of the beam, $s$ is the spacing of connectors and $K$ is the connector slip modulus.

$$
y_{c}=\left(1+\frac{\pi^{2} E_{c} A_{c} s}{K \cdot l^{2}}\right)^{-1}
$$

$$
a_{c}=\frac{\left(h_{c}+h_{w}\right)}{2}-a_{w}
$$

$$
a_{w}=\frac{y_{c} E_{c} A_{c}\left(h_{c}+h_{w}\right)}{2\left(y_{c} E_{c} A_{c}+y_{w} E_{w} A_{w}\right)}
$$

\subsubsection{A variational formulation for concrete-timber composite beams}

In the present work, the formulation presented in FORTI [11] and MASCIA et al. [12] was adopted. The formulation is based on the principle of virtual works. Therefore, it can be easily implemented in a computer solver using both the Finite Element Method (ODEN et al. [13]) and the Direct Stiffness Method (GERE and WEAVER [14]). Two consolidated theories for the analysis of beams are the Euler-Bernoulli's beam theory and the Timoshenko's beam theory (SLHESSARENKO [15]). In this work, the Euler-Bernoulli's beam theory in two dimensions was adopted.

\subsubsection{Principle of virtual work}

The principle of virtual work is adopted to formulate the problem. The composite beam is considered as two independent beams connected (one made of concrete and the other of wood). The strain energy of the composite structure is given as the sum of the strain energy of the two beams and the strain energy of the connectors. Thus, the internal

\section{Figure 3 - Kinematics of a composite beam}

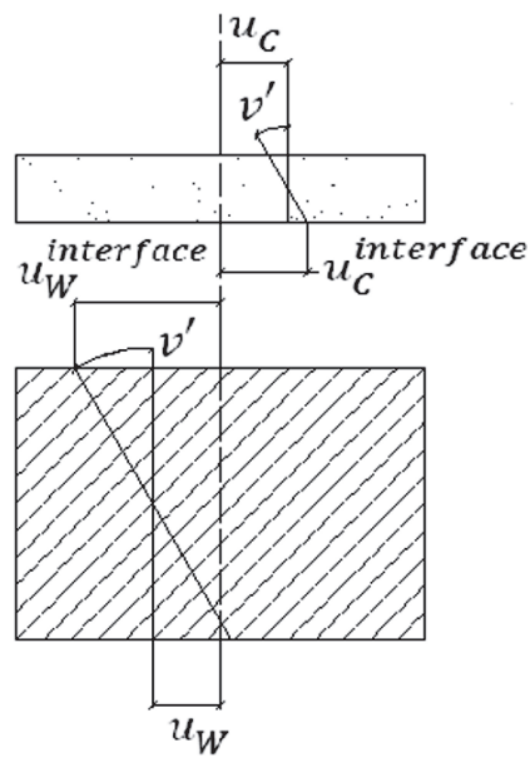

virtual work of the structure is the sum of the three individual internal virtual work, i.e., $T V_{i n t}^{C}+T V_{i n t}^{W}+T V_{i n t}^{S}=T V_{\text {ext }}$, where indices $\mathrm{C}, \mathrm{W}$ e S refer to concrete, wood, and connectors, respectively.

It is assumed the vertical displacement $(v(x))$ of the two beams are equal and therefore, their derivatives are equal too. Under Euler-Bernoulli's beam theory assumptions, the derivative of the vertical displacement is equal to the rotation of the cross section, and both beams have the same rotation $\theta^{C}=\theta^{W}=v^{\prime}(x)$. The shear force (force per unit of length) of the connectors is given as $T s=K \Delta u$, where $K$ is the slip modulus of the connectors and $\Delta u$ is the relative displacement between the lower fiber of the concrete beam and the upper fiber of the timber beam. Figure [3] illustrates this relative displacement.

The relative displacement $(\Delta u)$ is calculated as:

$$
\Delta u=u_{C}^{\text {interface }}-u_{W}^{\text {interface }}
$$

with

$$
\begin{aligned}
& u_{C}^{\text {interface }}=u_{C}+\theta_{C} \frac{h_{C}}{2} \\
& \mathrm{u}_{\mathrm{C}}^{\text {interface }}=\mathrm{u}_{\mathrm{C}}+\theta_{\mathrm{C}} \frac{\mathrm{h}_{\mathrm{C}}}{2} \mathrm{u}_{\mathrm{C}}^{\text {interface }}=\mathrm{u}_{\mathrm{C}}+\theta_{\mathrm{C}} \frac{\mathrm{h}_{\mathrm{C}}}{2} \\
& u_{W}^{\text {interface }}=u_{W}-\theta_{W} \frac{h_{W}}{2}
\end{aligned}
$$

Since the rotation of both beams are equal, then:

$$
\Delta u=u_{C}-u_{W}+v^{\prime}\left(\frac{h_{C}+h_{W}}{2}\right)
$$




\section{Figure 4 - A set of piecewise linear base functions}
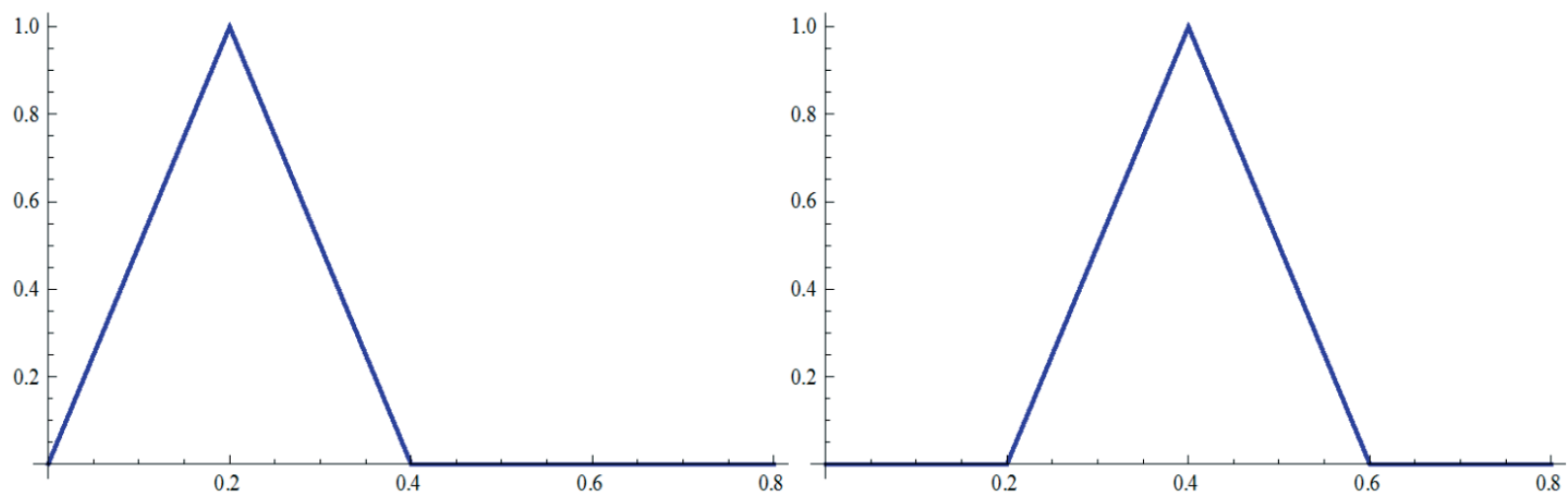

Defining $r$ the distance between the gravity center of the beams, it comes that:

$$
\begin{aligned}
& r=\left(\frac{h_{C}+h_{W}}{2}\right) . \\
& \text { and } T_{S}=K\left(u_{C}-u_{W}+v^{\prime} r\right)
\end{aligned}
$$

where the unknowns are the horizontal displacement of the fiber in the gravity center of the elements $u_{c}(x)$ and $u_{w}(x)$ and the vertical displacement $v(x) ; \delta u_{C}, \delta u_{W}$ and $\delta v$ are their respective virtual dsiplacements.

In FORTI [11], the variational formulation (Equation [9]) is solved using the Rayleigh-Ritz method. However, the Finite Element Method permits the application of this formulation to different types of load and geometries of beams in a more general fashion and simplicity of use. Moreover, this approach is more suited to be inserted in other software of structural analysis already available.

The internal virtual work of the connector is then given as:

$$
\begin{aligned}
& T V_{i n t}^{S}=\int_{0}^{L} T_{S} \delta \Delta u d s \\
& T V_{i n t}^{S}=\int_{0}^{L} K\left(u_{C}-u_{W}+v^{\prime} r\right)\left(\delta u_{C}-\delta u_{W}+\delta v^{\prime} r\right) d s
\end{aligned}
$$

Adding the internal virtual work of the connector to those of concrete and timber beams, the composite beam formulation is stated as:

$$
T V_{i n t}^{C}+T V_{i n t}^{W}+T V_{i n t}^{S}=T V_{e x t}
$$

with

$$
\begin{aligned}
& T V_{\text {int }}^{C}=\int_{0}^{L}\left(E_{C} A_{C} u_{C}{ }_{C} \delta u_{C}{ }^{\prime}+E_{C} I_{C} v^{\prime \prime} \delta v^{\prime \prime}\right) d s \\
& T V_{\text {int }}^{W}=\int_{0}^{L}\left(E_{W} A_{W} u_{W}^{\prime} \delta u_{W}{ }^{\prime}+E_{W} I_{W} v^{\prime \prime} \delta v^{\prime \prime}\right) d s \\
& T V_{\text {int }}^{S}=\int_{0}^{L} K\left(u_{C}-u_{W}+v^{\prime} r\right)\left(\delta u_{C}-\delta u_{W}+\delta v^{\prime} r\right) d s \\
& T V_{\text {ext }}=\int_{0}^{L} q \delta v d s+\sum_{i=1}^{N} P_{i} \delta v\left(x_{i}\right)
\end{aligned}
$$

\section{The finite element method}

The Finite Element Method consists in adopting functions to approximate the displacements $u_{c}(x), u_{w}(x)$ and $v(x)$ and also the virtual displacements $\delta u_{c}(x), \delta u_{w}(x)$ and $\delta v(x)$. Adopting approximating base functions, permits the calculation of an approximate solution to the variational problem of Equation [9]. In this work, two families of functions are employed: the piecewise linear functions and the cubic Hermite polynomials.

The piecewise linear base functions are defined as being linear functions that take value of 1 in one of the nodes of the mesh and zero in all the other nodes. Also known as hat functions, one example of two base functions is presented in Figure [4].

It can be noted the function has values different from zero in a

\section{Figure 5 - Linear shape functions of an element}

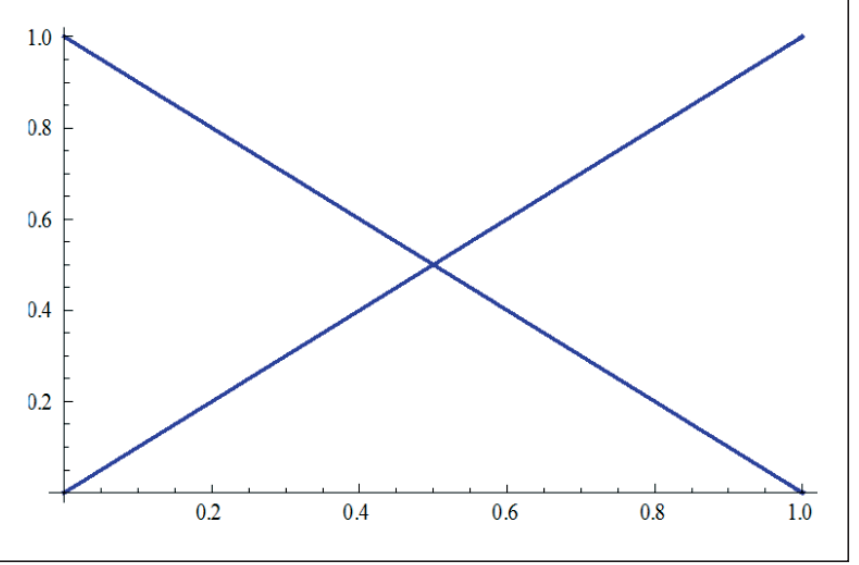




\section{Figure 6 - Cubic Hermite shape functions of an element}
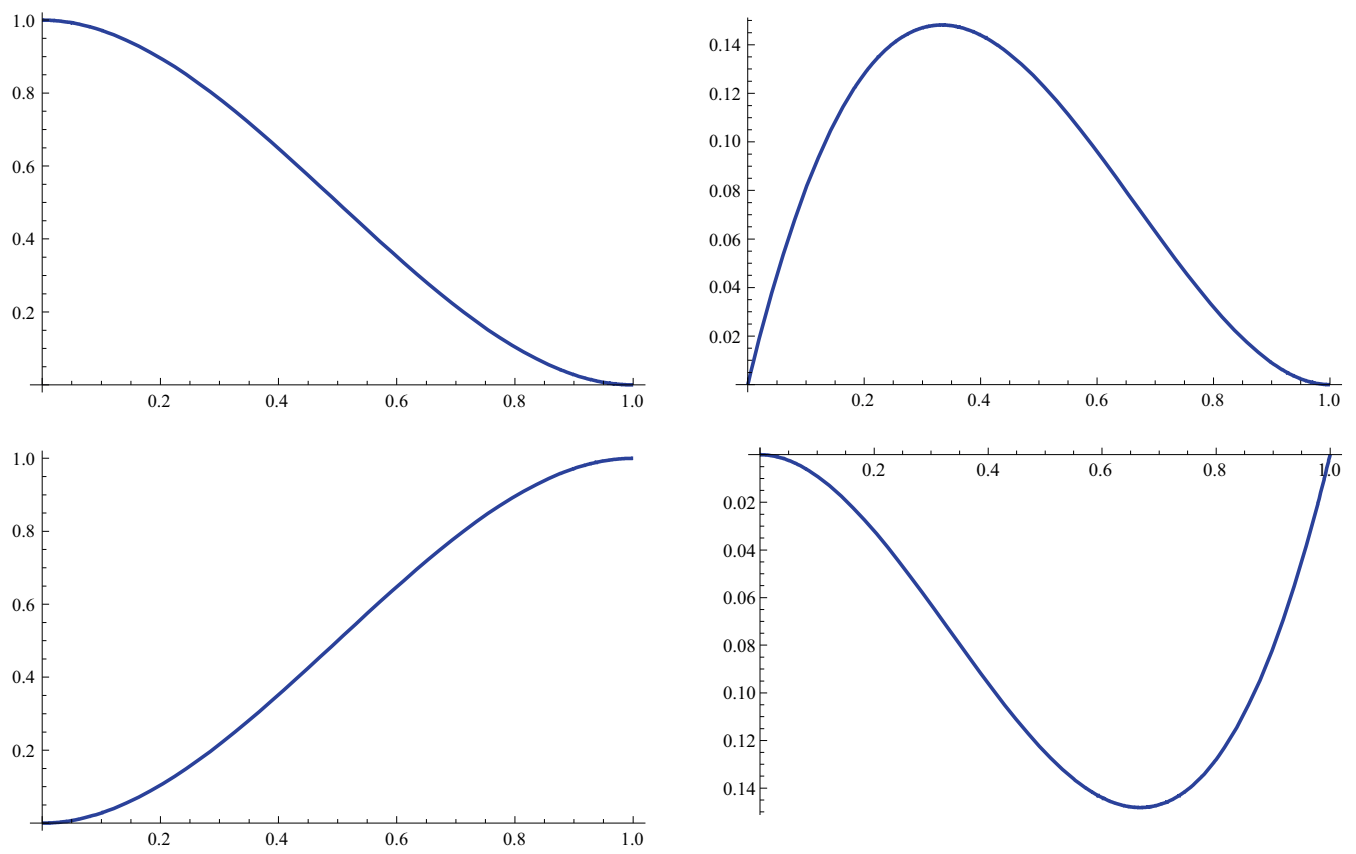

region formed by 3 nodes and has zero value in the rest of the domain. If each element of the mesh is formed by 2 nodes, then the function has local support to 2 neighbor elements and each element contributes with 2 functions, which are called shape functions of the element (Figure [5]). The local support property of the functions is employed in the construction of the element stiffness matrix.

The combination of the elements shape functions builds the approximate base functions. The defined linear functions has derivatives with piecewise constant values. Thus, the derivative of the function is discontinuous between elements. It means the first derivative of the piecewise linear function is integrable over the domain, but its second derivative would not be defined in the nodes of the mesh.

The cubic Hermite functions also have local support to the element and its neighbors. The properties of the Hermite functions involve the value of the function and its derivatives. The shape functions of one element are plotted in Figure [6].

The first function has the property of having value equal to 1 in the initial node of the element and zero in the final node. Additionally, its first derivative has zero value in both initial and final node. The second function has zero value in both nodes and its first derivative has value equal to 1 in the initial node and zero in the final node. The third function has value equal to 1 in the final node and the fourth function has value 1 for the first derivative in the final node, with zero value for the remaining values of function and first derivatives in the nodes. These functions are particularly important because they construct, in association to the neighbor elements, functions having the first derivative continuous over the whole domain. Thus, these functions are integrable up to their second derivatives.

The finite element formulation is obtained substituting the displacement functions by the approximating functions, i.e., $u_{w} \cong \sum_{j=1}^{n} \alpha_{j} \varphi_{j}$, $u_{w} \cong \sum_{j=1}^{n} \beta_{j} \varphi_{j}$, and $v \cong \sum_{j=1}^{m} \gamma_{j} \phi_{j}$. In the same manner, the virtual displacements are approximated by the same functions. Thus, the virtual displacement $\delta u_{c}$ is adopted as equal to each function

$\varphi_{i}$ and so on. Then, the finite element formulation is given as:

$$
T V_{\text {int }}^{C}+T V_{\text {int }}^{W}+T V_{\text {int }}^{S}=T V_{\text {eut }}
$$

where

$$
\begin{aligned}
& T V_{\text {int }}^{C}=\int_{0}^{L}\left(E_{C} A_{C}\left(\sum_{j=1}^{n} \alpha_{j} \varphi_{j}{ }^{\prime}\right) \varphi_{i, c}{ }^{\prime}+E_{C} I_{C}\left(\sum_{j=1}^{m} y_{j} \phi_{j}^{\prime \prime}\right) \phi_{i}^{\prime \prime}\right) d s \\
& T V_{i, h t}^{W}=\int_{0}^{L}\left(E_{W} A_{W}\left(\sum_{j=1}^{n} \beta_{j} \varphi_{j}^{\prime}\right) \varphi_{i, w}{ }^{\prime}+E_{W} I_{W}\left(\sum_{j=1}^{m} \gamma_{j} \phi_{j}^{\prime \prime}\right) \phi_{j}^{\prime \prime}\right) d s \\
& T V_{i n t}^{s}=\int_{0}^{L} K\left(\left(\sum_{j=1}^{n} \alpha_{j} \varphi_{j}\right)-\left(\sum_{j=1}^{n} \beta_{j} \varphi_{j}\right)+\left(\sum_{j=1}^{m} \gamma_{j} \phi_{j}^{\prime}\right) r\right)\left(\varphi_{i, c}-\varphi_{i, w}+\phi_{i}^{\prime} r\right) d s \\
& T V_{e x i}=\int_{0}^{L} q \phi_{i} d s+\sum_{i=1}^{M} P_{i} \phi_{i}\left(x_{i}\right)
\end{aligned}
$$

The variational formulation requires the calculation of integral that involves the first derivatives of the horizontal displacements $u_{c}$ and $u_{w}$. Thus, one can observe the piecewise linear functions (hat functions) satisfy the necessary requirements to approximate the horizontal displacements, since its first derivatives are integrable over the whole domain. Therefore, we adopted $\varphi_{j}$ as being hat functions, with the index $j$ indicating the node of the mesh where the function has value equal to 1 . The vertical displacement, however, requires the second derivative to be integrable in order to satisfy the variational formulation. Thus, the cubic Hermite functions are candidates to $\phi_{j}$, since their second derivatives are integrable 
over the domain. In this work, the Hermite functions are adopted as shape functions to approximate the vertical displacement $v(x)$. It is interesting to observe that in the Euler-Bernoulli's formulation, the rotation of the cross section is equal to the first derivative of the vertical displacement, i.e., $\theta(x)=v^{\prime}(x)$. Then, one may note that the first and third Hermite functions plotted in Figure [6] refer to the vertical displacement, while the second and fourth are related to the section rotation because they have first derivatives with values equal to 1 in the nodes.

Since the approximating functions have local support to the 2 neighboring elements connected to a node, the integrals over the domain $(0, L)$ are indeed calculated only over the elements of support of the function. The formulation can be written, in matrix form, as:

$$
[K]\{u\}=\{F\}
$$

where the matrix $\mathrm{K}$ is composed by the sum of the matrices of each element. The solution vector $u$ is given as:

$$
u=\left\{u_{c}^{1}, u_{w}^{1}, v^{1}, v^{1}, u_{c}^{2}, u_{w}^{2}, \ldots, u_{c}^{n}, u_{w}^{n}, v^{n}, v^{\prime n}\right\}^{T}
$$

which is the union set of the horizontal and vertical displacements and rotation of each node of the mesh $\left\{u_{c}, u_{w}, v, v^{\prime}\right\}$. The matrix of each element is described in the sequel.

\subsection{Element stiffness matrix}

The stiffness matrix is presented in parts, one for each term of the internal virtual work: concrete, wood and connector.

The stiffness matrix associated to the concrete element is given by the expression:

$$
K_{i j}^{c}=\int_{0}^{L}\left(E_{C} A_{C} \varphi_{j}{ }^{\prime} \varphi_{i, c}{ }^{\prime}+E_{C} I_{C} \phi_{j}{ }^{\prime \prime} \phi_{i}{ }^{\prime \prime}\right) d s
$$

which gives, for each element of the mesh of length $L_{e}$ :

$$
k_{i j}^{c}=\int_{0}^{L_{e}}\left(E_{C} A_{C} \varphi_{j}^{\prime} \varphi_{i, c}{ }^{\prime}+E_{C} I_{C} \phi_{j}^{\prime \prime} \phi_{i}^{\prime \prime}\right) d s
$$

or

$$
k_{e}^{c}=\left[\begin{array}{cccccccc}
\frac{A_{c} E_{c}}{L_{e}} & 0 & 0 & 0 & -\frac{A_{c} E_{c}}{L_{e}} & 0 & 0 & 0 \\
0 & 0 & 0 & 0 & 0 & 0 & 0 & 0 \\
0 & 0 & \frac{12 E_{c} I_{c}}{L_{e}^{3}} & \frac{6 E_{c} I_{c}}{L_{e}^{2}} & 0 & 0 & -\frac{12 E_{c} I_{c}}{L_{e}^{3}} & \frac{6 E_{c} I_{c}}{L_{e}^{2}} \\
0 & 0 & \frac{6 E_{c} I_{c}}{L_{e}^{2}} & \frac{4 E_{c} I_{c}}{L_{e}} & 0 & 0 & -\frac{6 E_{c} I_{c}}{L_{e}^{2}} & \frac{2 E_{c} I_{c}}{L_{e}} \\
-\frac{A_{c} E_{c}}{L_{e}} & 0 & 0 & 0 & \frac{A_{c} E_{c}}{L_{e}} & 0 & 0 & 0 \\
0 & 0 & 0 & 0 & 0 & 0 & 0 & 0 \\
0 & 0 & -\frac{12 E_{c} I_{c}}{L_{e}^{3}} & -\frac{6 E_{c} I_{c}}{L_{e}^{2}} & 0 & 0 & \frac{12 E_{c} I_{c}}{L_{e}^{3}} & -\frac{6 E_{c} I_{c}}{L_{e}^{2}} \\
0 & 0 & \frac{6 E_{c} I_{c}}{L_{e}^{2}} & \frac{2 E_{c} I_{c}}{L_{e}} & 0 & 0 & -\frac{6 E_{c} I_{c}}{L_{e}^{2}} & \frac{4 E_{c} I_{c}}{L_{e}}
\end{array}\right]
$$

The stiffness matrix associated to the timber element is given as:

$$
k_{e}^{w}=\left[\begin{array}{cccccccc}
0 & 0 & 0 & 0 & 0 & 0 & 0 & 0 \\
0 & \frac{A_{w} E_{w}}{L_{e}} & 0 & 0 & 0 & -\frac{A_{w} E_{w}}{L_{e}} & 0 & 0 \\
0 & 0 & \frac{12 E_{w} I_{w}}{L_{e}^{3}} & \frac{6 E_{w} I_{w}}{L_{e}^{2}} & 0 & 0 & -\frac{12 E_{w} I_{w}}{L_{e}^{3}} & \frac{6 E_{w} I_{w}}{L_{e}^{2}} \\
0 & 0 & \frac{6 E_{w} I_{w}}{L_{e}^{2}} & \frac{4 E_{w} I_{w}}{L_{e}} & 0 & 0 & -\frac{6 E_{w} I_{w}}{L_{e}^{2}} & \frac{2 E_{w} I_{w}}{L_{e}} \\
0 & 0 & 0 & 0 & 0 & 0 & 0 & 0 \\
0 & -\frac{A_{w} E_{w}}{L_{e}} & 0 & 0 & 0 & \frac{A_{w} E_{w}}{L_{e}} & 0 & 0 \\
0 & 0 & -\frac{12 E_{w} I_{w}}{L_{e}^{3}} & -\frac{6 E_{w} I_{w}}{L_{e}^{2}} & 0 & 0 & \frac{12 E_{w} I_{w}}{L_{e}^{3}} & -\frac{6 E_{w} I_{w}}{L_{e}^{2}} \\
0 & 0 & \frac{6 E_{w} I_{w}}{L_{e}^{2}} & \frac{2 E_{w} I_{w}}{L_{e}} & 0 & 0 & -\frac{6 E_{w} I_{w}}{L_{e}^{2}} & \frac{4 E_{w} I_{w}}{L_{e}}
\end{array}\right]
$$

It is interesting to observe that the stiffness matrices of the concrete and timber elements are, in fact, the same matrices one would obtain from the Direct Stiffness Method. Adding the two matrices, we would have the stiffness matrix in the case the elements were disassembled, where the bending stiffness would be added while the horizontal displacements would remain independent. The interaction between the two materials, with a consequent increase in the bending stiffness of the composite beam, is represented by the connector stiffness matrix. The connector matrix is calculated from the equation of internal virtual work of the connector:

$$
T V_{i n t}^{S}=\int_{0}^{L} K\left(u_{C}-u_{W}+v^{\prime} r\right)\left(\delta u_{C}-\delta u_{W}+\delta v^{\prime} r\right) d s
$$

which, being integrated over the domain of one element of length $L_{e}$, results in:

$$
k_{e}^{s}=\left[\begin{array}{cccccccc}
\frac{k L_{e}}{3} & -\frac{k L_{e}}{3} & -\frac{k r}{2} & \frac{k L_{e} r}{12} & \frac{k L_{e}}{6} & -\frac{k L_{e}}{6} & \frac{k r}{2} & -\frac{k L_{e} r}{12} \\
-\frac{k L_{e}}{3} & \frac{k L_{e}}{3} & \frac{k r}{2} & -\frac{k L_{e} r}{12} & -\frac{k L_{e}}{6} & \frac{k L_{e}}{6} & -\frac{k r}{2} & \frac{k L_{e} r}{12} \\
-\frac{k r}{2} & \frac{k r}{2} & \frac{6 k r^{2}}{5 L_{e}} & \frac{k r^{2}}{10} & -\frac{k r}{2} & \frac{k r}{2} & -\frac{6 k r^{2}}{5 L_{e}} & \frac{k r^{2}}{10} \\
\frac{k L_{e} r}{12} & -\frac{k L_{e} r}{12} & \frac{k r^{2}}{10} & \frac{2 k L_{e} r^{2}}{15} & -\frac{k L_{e} r}{12} & \frac{k L_{e} r}{12} & -\frac{k r^{2}}{10} & -\frac{k L_{e} r^{2}}{30} \\
\frac{k L_{e}}{6} & -\frac{k L_{e}}{6} & -\frac{k r}{2} & -\frac{k L_{e} r}{12} & \frac{k L_{e}}{3} & -\frac{k L_{e}}{3} & \frac{k r}{2} & \frac{k L_{e} r}{12} \\
-\frac{k L_{e}}{6} & \frac{k L_{e}}{6} & \frac{k r}{2} & \frac{k L_{e} r}{12} & -\frac{k L_{e}}{3} & \frac{k L_{e}}{3} & -\frac{k r}{2} & -\frac{k L_{e} r}{12} \\
\frac{k r}{2} & -\frac{k r}{2} & -\frac{6 k r^{2}}{5 L_{e}} & -\frac{k r^{2}}{10} & \frac{k r}{2} & -\frac{k r}{2} & \frac{6 k r^{2}}{5 L_{e}} & -\frac{k r^{2}}{10} \\
-\frac{k L_{e} r}{12} & \frac{k L_{e} r}{12} & \frac{k r^{2}}{10} & -\frac{k L_{e} r^{2}}{30} & \frac{k L_{e} r}{12} & -\frac{k L_{e} r}{12} & -\frac{k r^{2}}{10} & \frac{2 k L_{e} r^{2}}{15}
\end{array}\right]
$$

Finally, the element stiffness matrix of a concrete-timber composite beam is given as $k=k^{c}+k^{w}+k^{s}$.

The load vector is obtained from the external virtual work, which in this study is given as:

$$
T V_{e x t}=\int_{0}^{L} q \delta v d s+\sum_{i=1}^{N} P_{i} \delta v\left(x_{i}\right)
$$

where $q$ is a distributed vertical force and $P_{i}$ are vertical forces applied to nodes. It is to be noted that only vertical loads were considered in Equation 16, although its extension to other types of loads is trivial. The load vector for a $q$ constant valued along the element is given by: 


$$
F=\left\{0,0, \frac{L_{e} q}{2}, \frac{L_{e}^{2} q}{12}, 0,0, \frac{L_{e} q}{2},-\frac{L_{e}^{2} q}{12}\right\}^{T}
$$

The nodal concentrated forces $P_{i}$ are added to the algebraic problem by adding their values in their respective positions of the global load vector.

\subsection{Computational solver}

The solver is implemented on $\mathrm{C}++$ language, using some classes from the finite element library PZ (DEVLOO [16]). In order to facilitate the use of the program, a graphical interface was implemented to input data and visualize results. Figure [7] shows the main screen of the program with the data to be input. The result graphics are the vertical displacement of the composite beam, bending moment and normal forces of each of the two beams and the connector shear force.

The implementation was verified comparing its results to the results presented in FORTI [11]. FORTI [11] presents some numerical results of the variational formulation and an analytical solution of the differential equation from STEVANOVIC [17]. The results are also compared to the experimental data of laboratory tests (SORIANO [4]), with good agreement of results.

\section{Results and discussions}

The developed program is applied to the problem of a concretetimber beam presented in FORTI [11] for verifying the finite ele-

\section{Table 1 - Properties of the components of the composite beam}

\begin{tabular}{|c|c|c|}
\hline & Concrete & Timber \\
\hline Cross section area $\left(\mathrm{mm}^{2}\right)$ & 12,000 & 7,500 \\
\hline Moment of inertia $\left(\mathrm{mm}^{4}\right)$ & $1,6 \times 10^{6}$ & $14.063 \times 10^{6}$ \\
\hline $\mathrm{E}^{*}\left(\mathrm{~N} / \mathrm{mm}^{2}\right)$ & 19,300 & 14,700 \\
\hline \multicolumn{3}{|c|}{$\begin{array}{l}\text { *Longitudinal Young's modulus obtained from a compressive test parallel to the } \\
\text { fiber direction. } \\
\text { Connector slip modulus under service loading: } \\
\text { Klc (ser) }=15.464 \mathrm{~N} / \mathrm{mm} \text {; } \\
\text { Connector spacing }(\mathrm{s})=7.5 \mathrm{~cm} \text {. }\end{array}$} \\
\hline
\end{tabular}

ment solver implemented. The results are also compared to those obtained from the routines of the EUROCODE 5 [9].

The input data is described in Table [1] and in Figures [8] and [9]. The connection between the two materials was made with 41 hex bolts of $1 / 2$ ", with spacing of $7.5 \mathrm{~cm}$. The slip modulus was obtained from shear laboratory tests. SORIANO [4] performed 5 tests and the average slip modulus under service load obtained was equal to $\mathrm{K}_{\text {ser }}=15464 \mathrm{~N} / \mathrm{mm}$. The ultimate modulus was $\mathrm{K}_{\mathrm{u}}=10309 \mathrm{~N} / \mathrm{mm}$ In the experimental test of SORIANO [4], there were two loads to be considered (Figure [8]): one uniformly distributed load, correspondent to the self-weight of the beam $q=0.36 \mathrm{~N} / \mathrm{mm}$, and a concentrated force $P_{k}$ applied vertically in the middle of the beam. The vertical displacement was measured from the moment the concentrated force was applied, i.e., the measured displacement does not include the vertical displacement caused by the self-weight of the

\section{Figure 7 - Main screen of the program: input data and results}

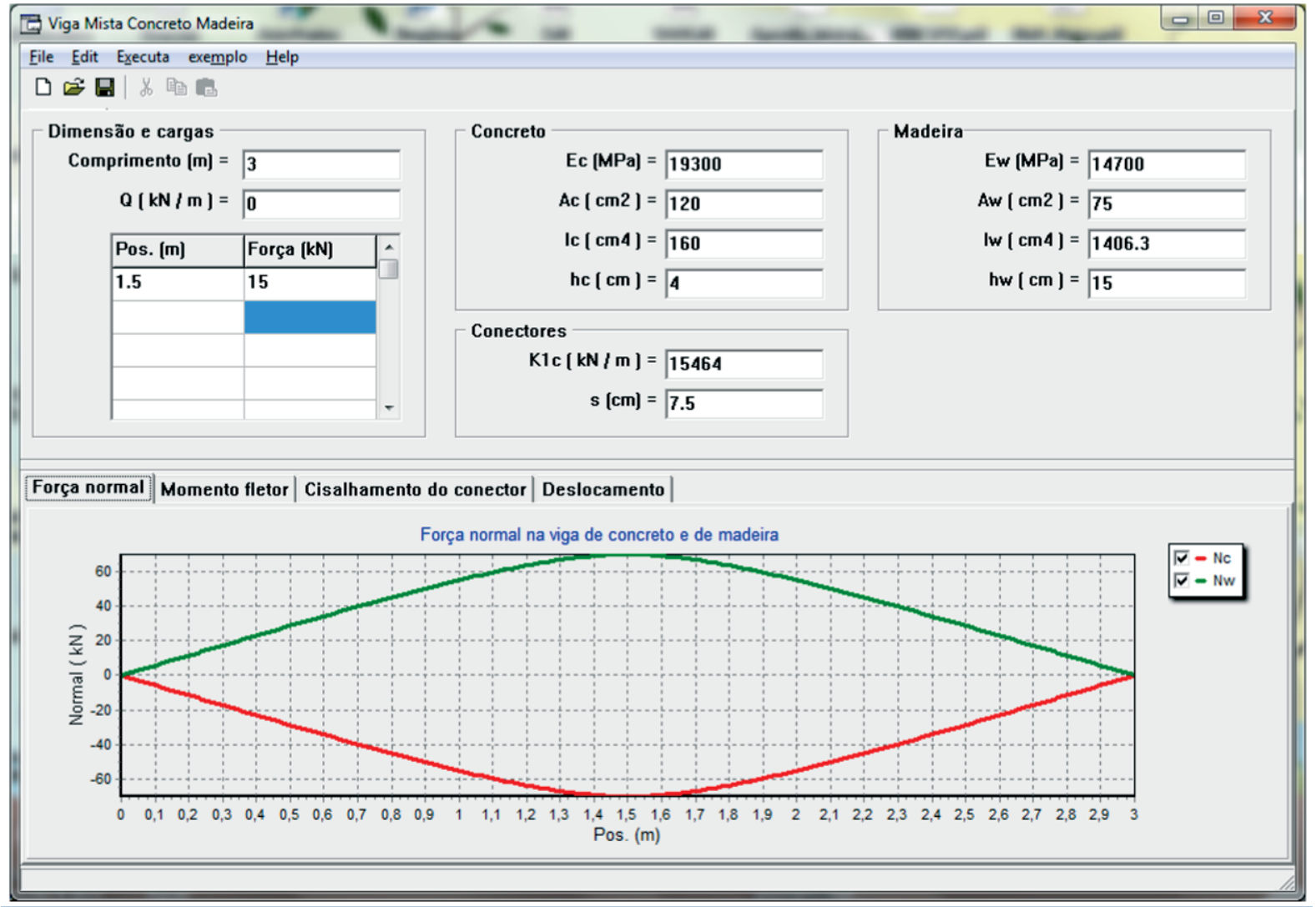




\section{Figure 8 - Geometry of the tested composite beams (dimensions in cm). (SORIANO (4))}
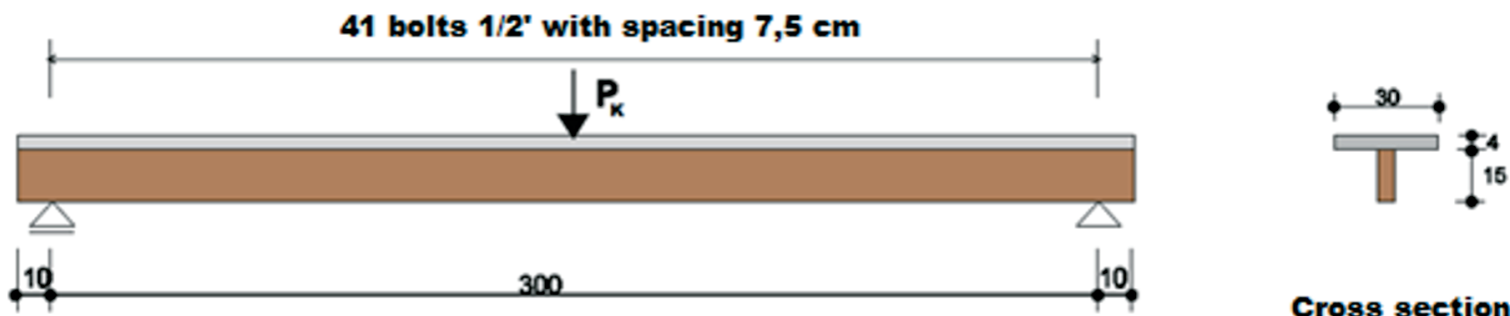

Cross section

\section{Side view}

Figure 9 - Boundary conditions of the tested beams

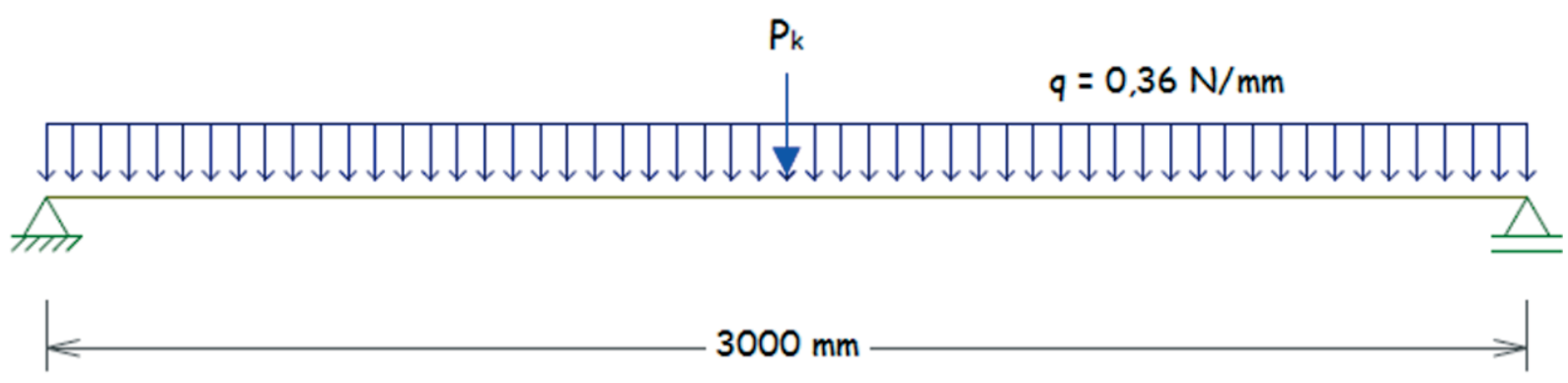

beam. Therefore, in the numerical analysis, only the concentrated force is simulated. This procedure is mathematically valid due to the linearity of the formulation adopted.

Table [2] complements the input data with the values of the force $P_{k}$, which varied from 0 to $30 \mathrm{kN}$, and brings the comparison of the results obtained in this work to those obtained from the literature. Table [2] brings the following results:

1. SORIANO [4]: the displacements from the two experimental tests (Exp. 1, Exp. 2, and the average values of the tests). It is worth noting that the structure collapsed in Exp. 1 and Exp. 2

\section{Table 2 - Results of vertical displacements at $L / 2$ of the composite beam}

\begin{tabular}{|c|c|c|c|c|c|c|c|c|c|}
\hline \multirow{2}{*}{$\begin{array}{c}\text { Load } \\
(\mathrm{kN}) \\
\text { Pk }\end{array}$} & \multicolumn{3}{|c|}{$\begin{array}{l}\text { Experimental } \\
(\mathrm{mm})\end{array}$} & \multicolumn{4}{|c|}{$\begin{array}{l}\text { Numerical } \\
(\mathrm{mm})\end{array}$} & \multicolumn{2}{|c|}{$\begin{array}{c}\text { Analytical } \\
(\mathrm{mm})\end{array}$} \\
\hline & Exp. 1 & Exp.2 & Average & FORTI (11) & Difference' & FEM & Difference ${ }^{2}$ & Eurocode 5 & Difference $^{3}$ \\
\hline 0 & 0 & 0 & 0 & 0 & $0 \%$ & 0 & $0 \%$ & 0 & $0 \%$ \\
\hline 5 & 4.13 & 4.43 & 4.28 & 3.96 & $7.5 \%$ & 3.96 & $7.5 \%$ & 3.91 & $8.6 \%$ \\
\hline 10 & 8.34 & 8.72 & 8.53 & 7.92 & $7.2 \%$ & 7.92 & $7.2 \%$ & 7.81 & $8.4 \%$ \\
\hline 15 & 12.26 & 13.01 & 12.64 & 11.88 & $6.0 \%$ & 11.88 & $6.0 \%$ & 11.72 & $7.2 \%$ \\
\hline 20 & 16.76 & 17.76 & 1.26 & 15.84 & $8.2 \%$ & 15.85 & $8.2 \%$ & 15.62 & $9.5 \%$ \\
\hline 25 & 22.94 & 23.68 & 23.31 & 19.80 & $15.1 \%$ & 19.80 & $15.1 \%$ & 19.53 & $16.2 \%$ \\
\hline 30 & 30.61 & 29.08 & 29.85 & 23.76 & $20.4 \%$ & 23.76 & $20.4 \%$ & 23.44 & $21.5 \%$ \\
\hline
\end{tabular}

Difference $^{1}=\frac{F O R T I[11]-\text { experimental average }}{\text { experimentalaverage }} \quad$ Difference $^{2}=\frac{F E M-\text { experimental average }}{\text { experimentalaverage }}$

Difference $^{3}=\underline{\text { Eurocode } 5-\text { experimental average }}$

experimentalaverage 


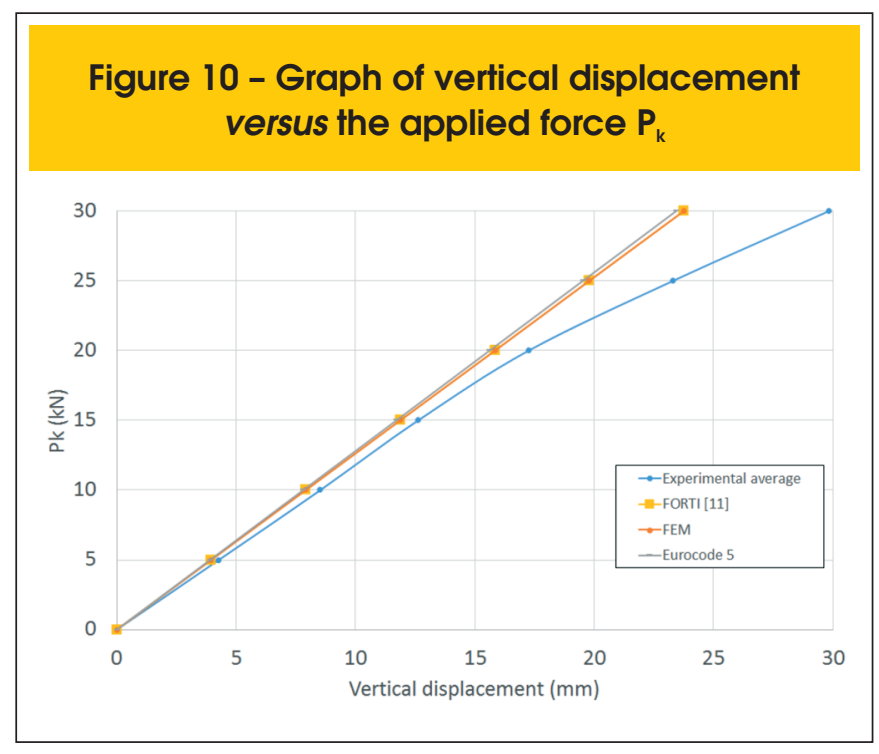

when $P_{k}$ was equal to $37.811 \mathrm{kN}$ and $36.694 \mathrm{kN}$, respectively;

2. FORTI [11]: the results obtained from the variational formulation solved using the Rayleigh-Ritz method;

3. The results obtained in this work using the implemented finite element solver (FEM);

4. Calculating using the routines of the EUROCODE 5 [9], which defines an effective bending stiffness parameter (Equation 1). For this case the effective stiffness $(E I)_{e f}=720.0542 \mathrm{kN} . \mathrm{m}^{2}$ and the vertical displacement is calculated as $\frac{P_{k} L^{3}}{48(E I)_{e f}}$.

Table [2] also brings the comparison of the displacements calculated by the different methodologies and the experimental results. Figure [10] illustrates the comparison of results shown in Table [2]. It can be observed that the displacement curve from the experimental tests indicates a non-linear behavior beyond the point where the force is $P_{k}=20 \mathrm{kN}$.

Analyzing the data of Table [2], one can observe that:

- The finite element solution (FEM) of this work is equal to the solution of FORTI [11]. This conclusion was expected, since both works solve the same variational formulation. The agreement of results, in fact, verify the $\mathrm{C}++$ code implemented, at least for this example.

- The numerical results are very similar to the experimental results, conclusion already observed in FORTI [11]. The values differ from less than $10 \%$ in the early stages of loading. With the increase of the load $P_{K}$, it can be observed the influence of the non-linear behavior of the materials and the consequent deviation of the results with a maximum difference of about $20 \%$ when $P_{k}=30 \mathrm{kN}$, near the point of collapse of the tested beams. This result evidences the quality of the variational formulation in representing the physical phenomenon while the structure is in the elastic domain.

- The results from the routines of the EUROCODE 5 [9] are in great agreement with the numerical solutions, with differences inferior to $1.5 \%$. This is an evident quality of the analytical formulation, much simpler to be used.

The other results of the implemented program are presented in Figures [11], [12], [13], and [14] for the simulation with $P_{k}=15 \mathrm{kN}$. Figure [11] shows the vertical displacement of the composite beam. Figure [12] brings the curves of the bending moment for the concrete beam $\left(M_{c}\right)$, the timber beam $\left(M_{w}\right)$ and the total bending moment $\left(M_{\text {total }}\right)$. Figure [13] shows the graphics of normal forces. In the absence of interaction between the two beams, the sum of the bending moment of the concrete beam to the moment of the timber beam would be equal to the total bending moment. Thus, it is interesting to observe that the interaction between the beams reduce the bending moment acting on each of the beams. However, there is the appearance of normal forces, which cancel each other. The normal force in the concrete beam is of compression and in the timber beam is of tension.

Figure [14] presents the shear force of the connectors.

\section{Figure 11 - Graph of vertical displacement along the length of the beam for the applied force of $P_{k}=15 \mathrm{kN}$}

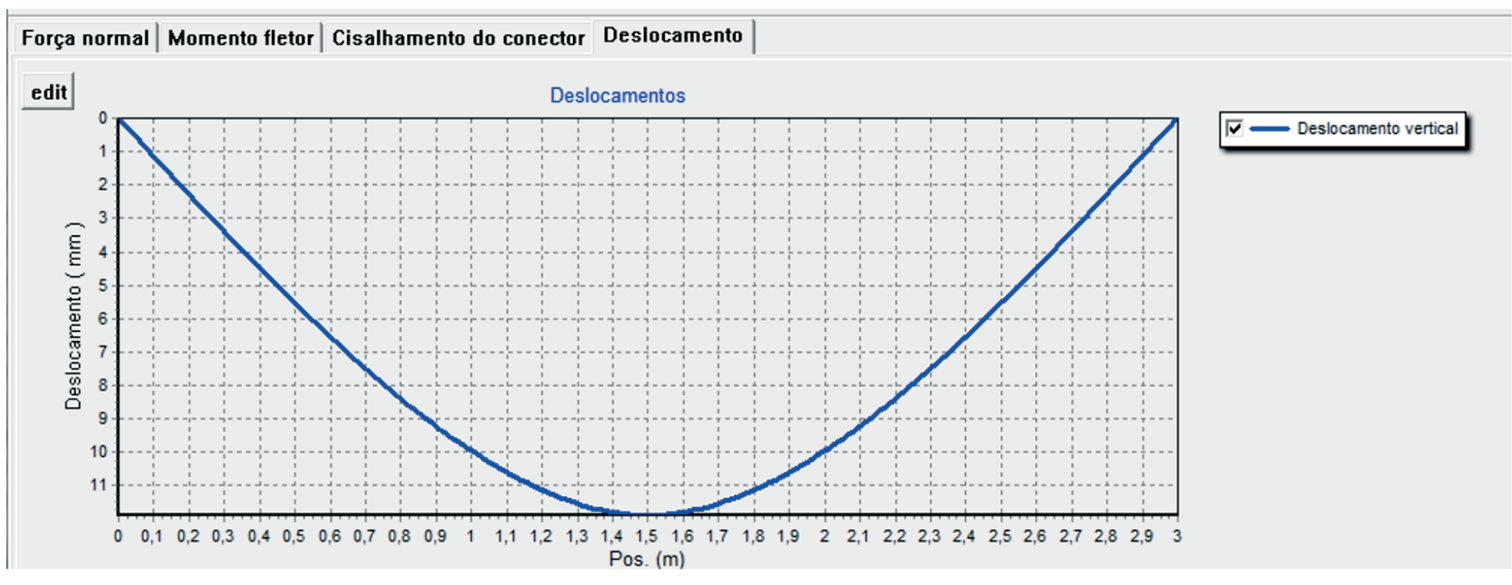


Figure 12 - Graph of bending moment of each of the beams (concrete and timber) and the total moment for the applied force of $P_{k}=15 \mathrm{kN}$

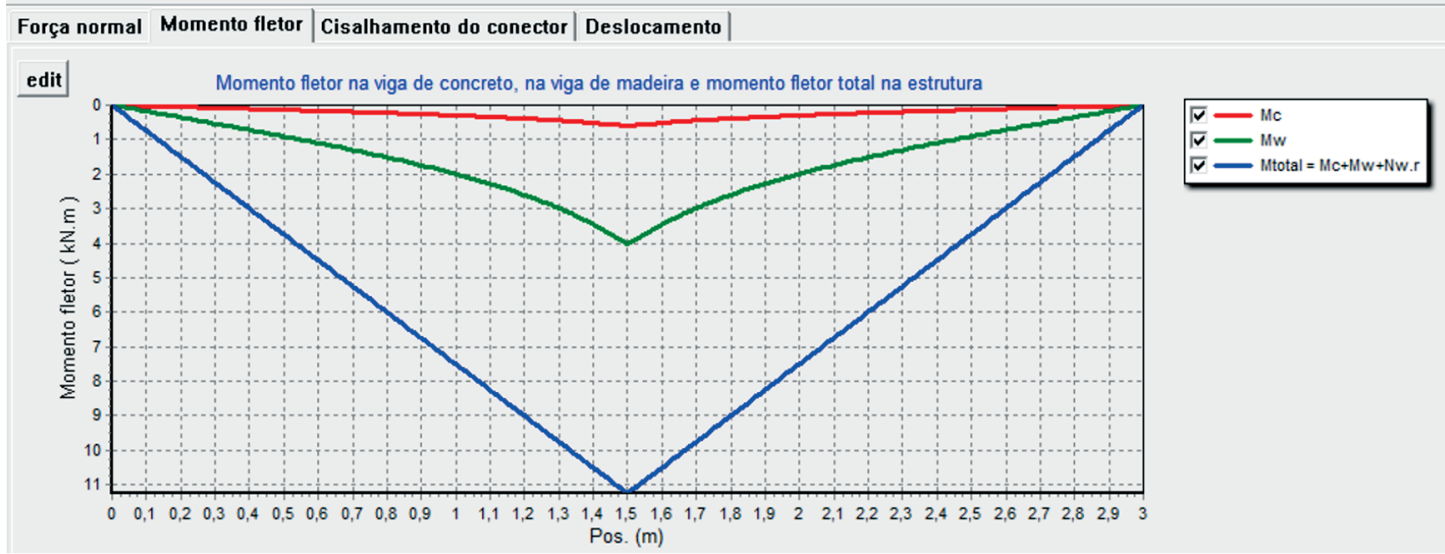

Figure 13 - Graph of normal forces on the concrete and timber beams for the applied force of $P_{k}=15 \mathrm{kN}$

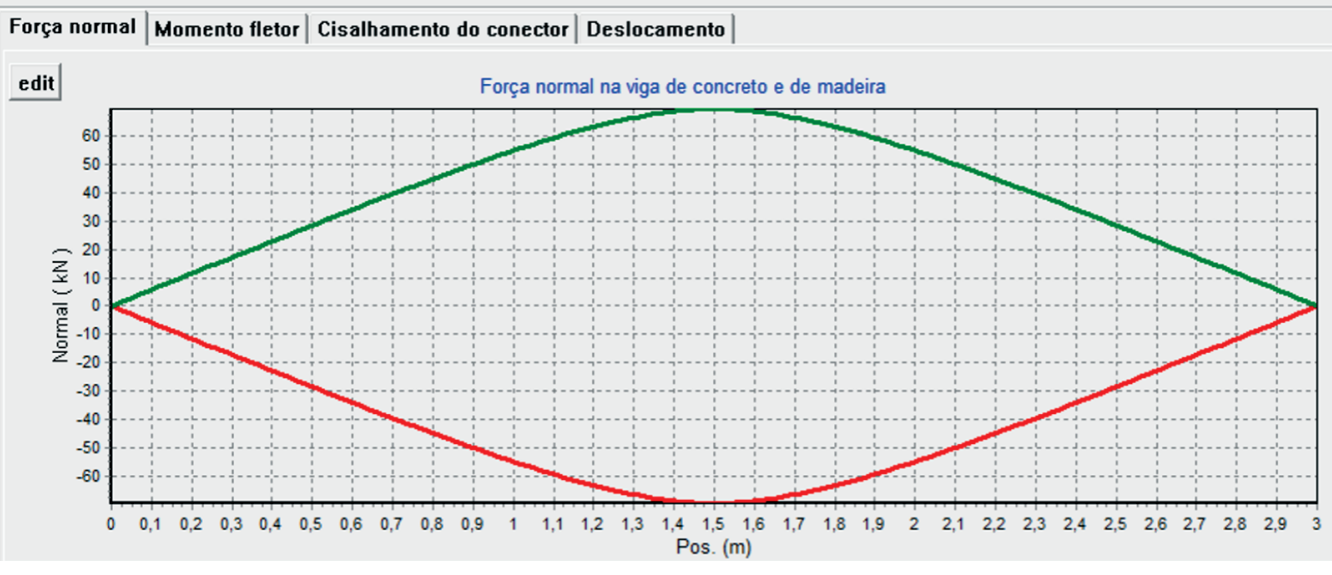

Figure 14 - Graph of the connection shear force along the length of the beam for $P_{k}=15 \mathrm{kN}$

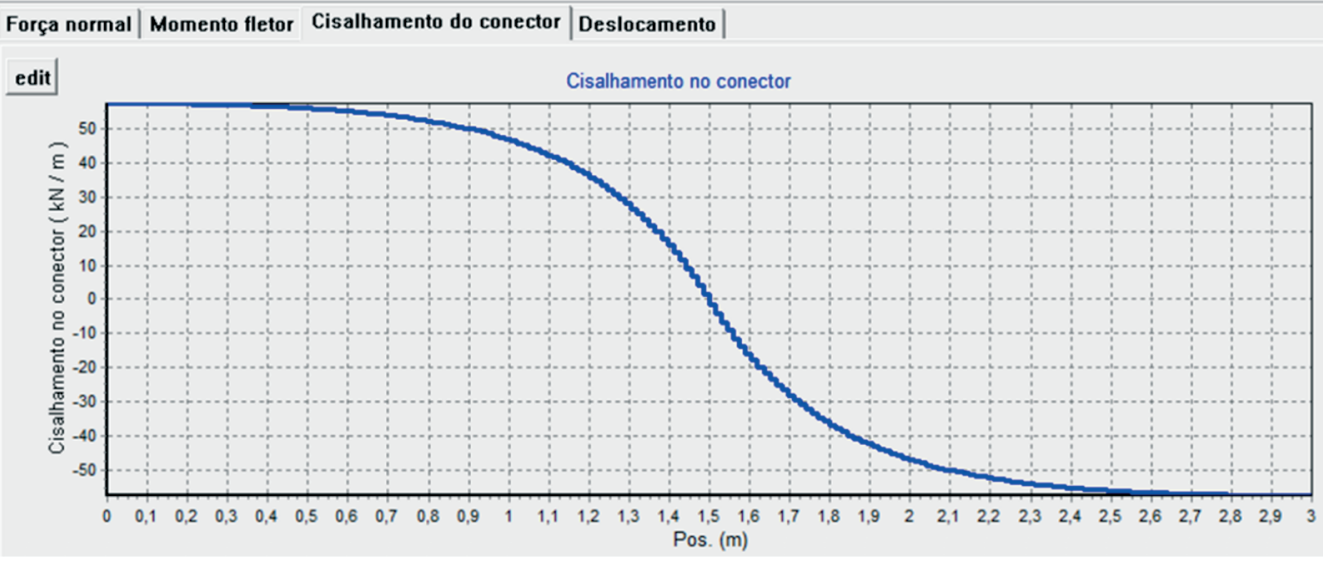




\section{Conclusions}

The technological development of the process of design and construction of timber structures has improved the knowledge of the behavior of this material and its subsequent use in composite structures. The employment of composite concrete-timber structures promotes the best use of the features of each material.

This work contributes with an analysis of concrete-timber composite beams. Two approaches for calculating the stress state of the beam are compared. One is based on a finite element formulation and the other is based on the analytical procedure of the standard EUROCODE 5 .

The variational formulation, based on the principle of virtual work, accounts to the strain energy of the three main components of a composite beam: the reinforced concrete slab, the timber web and the connectors (or fasteners). The formulation is consistent and satisfies the equilibrium equations. It is coherent with laboratory test results.

The procedure of the EUROCODE 5 is based on an effective bending stiffness, which is function of the components of the composite beam, specially the slip modulus of connectors.

The implementation of a finite element formulation enables the use of the formulation in structural analysis programs. A software with user interface was developed and it is available to the community. Some examples were performed to compare the simulation results to the results obtained from the procedure of the EUROCODE 5. It is observed great concordance of the results, which differ from less than $1.5 \%$.

This development promotes, through the development of the computational program, a wider propagation of the procedures of design and the understanding of the mechanical behavior of composite beams, which may catalyze the use of this type of structure. The finite element formulation presented may be applied to other types of composite structures, for instance, a structure with a steel profile web associated to a concrete slab.

\section{References}

[1] CECCOTTI, A. Timber-concrete composite structures. In: Timber Engineering - STEP1. BLASS, H. J., AUNE, P., CHOO, B.S. et al., Almere: Centrum Hout, 1995, E13, p.1-12.

[2] TARANTINO, A. M., DEZI, L. Creep effects in composite beams with flexible shear connectors. Journal of Structural Engineering- ASCE, New York, n. 8, v.118, p.2063-2081. Aug. 1992.

[3] RACHER, P. Mechanical timber joints - general. In: Timber Engineering - STEP lecture C1. BLASS, H. J., AUNE, P., CHOO, B.S. et al., Almere: Centrum Hout, 1995, C1, p.1-10.

[4] SORIANO, J. Estruturas mistas de concreto e madeira: Análise de vigas e painéis e aplicações na construção civil. In Tese (Doutorado em Engenharia Civil) - Faculdade de Engenharia Civil, Universidade Estadual de Campinas, 2001.

[5] GIRHAMMAR, U. A., GOPU, V. K. A. Composite beam-columns with interlayer slip-exact analysis. Journal of Structural Engineering-ASCE, New York, n. 4, v.119, p.1265-1282. Apr. 1993.

[6] NICOLAS, E. A. Estudo de ligações em estruturas mistas de concreto-madeira. Universidade Estadual de Campinas - Faculdade de Engenharia Civil, Dissertação, 2001, p 103.
[7] BS 5400-5: Steel, concrete and composite bridges. Code of practice for design of composite bridges. (AMD 3998) (withdrawn), 1979

[8] NBR 8800: Projeto de Estruturas de aço e de estruturas mistas de aço e concreto de edifícios. Setembro, 2008.

[9] EUROCODE 5 (prEN 1995-1-1): Design of timber structures. Part 1-1: General - common rules and rules for buildings. Brussels, 2008.

[10] DIN 1052: Structural use of timber - part 1, 2 and 3. Berlin, 1988.

[11] FORTI, N. C. S. Análise numérica de vigas mistas em concreto e madeira. 2004. Tese (Mestrado) - Faculdade de Engenharia Civil, Universidade Estadual de Campinas, Campinas, 2004.

[12] MASCIA, NILSON T.; FORTI, NÁDIA C.S. ; SORIANO, JULIO ; NICOLAS, ELIAS A. ; FORTI, TIAGO L.D. . Study of concrete-timber composite beams using an analytical approach based on the principle of virtual work and experimental results. Engineering Structures, v. 46, p. 302-310, 2013.

[13] ODEN, J. T., CAREY G. F. e BECKER E. B. Finite Elements - An introduction. Vol 1. Prentice Hall Inc. USA. 1981.

[14] GERE, J. M. e WEAVER, W. Analysis of framed structures. 1965.

[15] SLHESSARENKO, F. L. - Análise tridimensional de edifícios por elementos finitos utilizando programação orientada a objetos. 1997. Tese (Mestrado) - Faculdade de Engenharia Civil, Universidade Estadual de Campinas, Campinas, 1997.

[16] DEVLOO, P. R. B. . PZ An Object Oriented Environment For Scientific Programming. COMPUTER METHODS IN APPLIED MECHANICS AND ENGINEERING, v. 150, n.1-4, p. 133-153, 1997.

[17] STEVANOVIC, B. Elastically coupled timber-concrete beams. In INTERNACIONAL WOOD ENGINEERING CONFERENCE, 1996, New Orleans. Proceedings... New Orleans, Oct. 1996. v.3. p.425-430. 